\title{
O processo de modernização portuária e a produção de subjetividade: o caso do porto de Santos
}

\author{
Maria de Fátima Ferreira Queiroz ${ }^{\mathrm{I}, 1}$, \\ Maria Inês Badaró Moreira ${ }^{\mathrm{I}, 2}$ e Maristela Dalbello-Araujo ${ }^{\mathrm{II}, 3}$ \\ ${ }^{\mathrm{I}}$ Universidade Federal de São Paulo (Santos, SP)

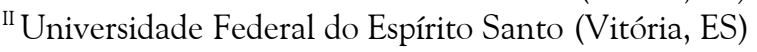

\begin{abstract}
Este artigo trata de parte dos resultados de pesquisa realizada por equipe interdisciplinar sobre o processo de modernização do porto da cidade de Santos-SP e suas implicações na saúde e no adoecimento dos trabalhadores. Destaca a produção de subjetividade no contexto do trabalho portuário, uma vez que as transformações ocorridas estão marcadas na vivência de cada trabalhador e na vida de todo o coletivo de trabalhadores. Foram entrevistados 30 trabalhadores com idade entre 34 e 67 anos. As entrevistas semiestruturadas foram transcritas e submetidas a análise de conteúdo. Os resultados apontam para um universo peculiar do trabalho em que a modernidade e a tecnologia ainda são dependentes da intervenção física do trabalhador. Assim, corpo e saúde dos trabalhadores garantem a manutenção da produtividade portuária, mas sem que eles se sintam valorizados pelo trabalho. $\mathrm{O}$ contexto em transformação, desde a década de 1990, tem permitido aos trabalhadores, por meio de sua ação, produzir serviços e também produzir um novo modo de significar o trabalho e as relações ali constituídas. Ou seja, há um processo em que, ao mesmo tempo em que se produz o trabalho, os trabalhadores são produzidos por ele.
\end{abstract}

Palavras-chave: Trabalho portuário, Subjetividade, Saúde do trabalhador.

The port modernization process and the production of subjectivity: the Port of Santos case

This article deals with some results from a large research conducted by an interdisciplinary team on the process of modernization of the port of Santos, in the State of São Paulo, and its implications on health and illness among workers. It focus on the production of subjectivity in the context of dock work, since the transformations that occurred mark the experience of each worker and the lives of the entire group of workers. Thirty workers aged between 34 to 67 years were interviewed. The semi-structured interviews were transcribed and submitted to content analysis. The results point to a peculiar universe of the work in which modernity and technology depend on workers' physical intervention. Thus, workers' body and health ensure the maintenance of port productivity, but they do not feel valued at work. The changing context since the 1990s has allowed workers, through their own actions, to produce services and also to produce a new way to create meaning to the work and the relationships formed there. That is, there is a process in which work is produced and, at the same time, workers are produced by work.

Keywords: Dock work, Subjectivity, Work health.

\section{Introdução}

$\mathrm{O}$ porto de Santos tem importante função para o desenvolvimento econômico da cidade e de toda a região da Baixada Santista. Começou a operar em 1532, devido a suas águas tranquilas e profundas. Para Araújo e Pereira (2007), a cidade de Santos só alcançou a emancipação comercial quando o porto tornou-se o mais importante do Brasil, com o crescimento da exportação do café na primeira metade do século XIX. A inauguração da

1 Doutora em Saúde Pública. Departamento de Políticas Públicas e Saúde Coletiva, Laboratório de Estudos Interdisciplinares em Trabalho e Saúde na Contemporaneidade, Universidade Federal de São Paulo, Instituto de Saúde e Sociedade, Campus Baixada Santista.

2 Doutora em Psicologia. Departamento de Políticas Públicas e Saúde Coletiva, Laboratório de Produção do Conhecimento Compartilhado em Saúde Mental, Universidade Federal de São Paulo, Instituto de Saúde e Sociedade, Campus Baixada Santista.

3 Doutora em Psicologia. Programa de Pós-Graduação em Saúde Coletiva, Núcleo de Estudos em Saúde Coletiva, Universidade Federal do Espírito Santo, Vitória, ES. 
ferrovia ligando São Paulo ao Rio de Janeiro favoreceu o comércio direto com portos estrangeiros. Contudo, suas instalações eram bastante precárias, e a cidade "era um imenso depósito a céu aberto" onde se despejavam mercadorias: "O ambiente era extremamente desagradável. Ao lixo, juntava-se o excremento dos animais de carga e de tração" (p. 89).

Até a abolição da escravatura, grande parte de sua mão de obra era formada por escravos. Logo após 1888, o trabalho portuário, em sua maior parte, passou a ser realizado por ex-escravos. Em 1880, a exploração do Porto de Santos foi entregue à iniciativa privada, com monopólio mantido até 1980, quando passou seu controle para o gestor público federal, com a criação da Companhia Docas do Estado de São Paulo - CODESP (Aguiar, Junqueira \& Freddo, 2006).

A sua estruturação e o saneamento da cidade se deram de maneira interligada e contribuíram para o importante processo de reorganização do trabalho, assim como da própria cidade, no início do século XX (Gitahy, 1992; Merhy, 1985). O Porto de Santos é considerado o maior porto da América Latina, com funcionamento atual de 13 quilômetros de cais entre as duas margens de seu estuário (Gonçalves \& Nunes, 2008). Além disso, vem se destacando tanto do ponto de vista das operações comerciais como no âmbito do turismo marítimo nacional e internacional.

A história político-econômica do trabalho no Porto de Santos, desde seus primórdios, envolve a atuação de trabalhadores portuários avulsos. Esta modalidade de vínculo tem como particularidade o fato de o trabalhador fazer parte do coletivo daqueles considerados aptos para a tarefa. Entretanto, cabe a cada um, individualmente, a opção de oferecer-se ou não para a atividade específica em determinado turno. Ao fazê-lo, concorre com os demais que estão na mesma condição; por outro lado, isso permite maior liberdade para a escolha das tarefas e dos períodos de trabalho, diferentemente das relações trabalhistas instituídas (Gonçalves \& Nunes, 2008).

A partir da década de 1970, os portos brasileiros passaram por um processo de modernização como consequência da introdução de novas tecnologias no embarque e desembarque de cargas e em resposta à nova forma de arranjo destas cargas, que passaram a ser embarcadas em contêineres. Este mecanismo fez com que a carga - que anteriormente seguia solta - passasse a ser embarcada em contêiner: isso recebe o nome de unitização de cargas, ou seja, torná-la uma única unidade de carga no navio.

Posteriormente, houve alteração das formas de trabalho e do gerenciamento dos portos, originando uma nova fase de exploração estabelecida pela Lei de Modernização dos Portos - Lei 8.630/1993, que possibilitou o arrendamento de áreas e instalações à iniciativa privada (Codesp, s.d.). Com a implementação desta lei, houve transformações na estruturação e no controle do trabalho e dos trabalhadores portuários, que passaram a ser administrados pelo Órgão Gestor de Mão de Obra - OGMO. Este órgão tornou-se responsável pela divisão e escala dos trabalhadores portuários avulsos para o porto. Entretanto, mesmo com tantas mudanças, mantém-se o importante papel do porto na vida econômica da região, tendo em vista o número de trabalhadores envolvidos direta e indiretamente na atividade portuária, sejam eles avulsos ou vinculados às operadoras portuárias (Junqueira, 2002).

Com a globalização da economia, a competitividade passou a ser a regra básica para sobrevivência no mercado, o que acarretou mudanças em vários setores produtivos, atingindo o transporte de cargas marítimas. Sendo assim, os portos tiveram de se enquadrar às normas mundiais. Este novo arranjo e as exigências de internacionalização dos portos produziram modificações que afetaram o sentido de apropriação do trabalho, os sentimentos gerados pelo trabalho e a própria valorização do trabalhador, o que trouxe implicações na saúde e no adoecimento da categoria (Dalbello-Araujo, 2001). 
Não há dúvidas de que se trata de um momento histórico de mudanças na lógica portuária. Assim, a internacionalização do Porto de Santos e a implementação de novas tecnologias no embarque e desembarque de cargas são objetivos visíveis nas ações governamentais e afetam o cotidiano dos trabalhadores portuários (Freddo, 2002).

As transformações em curso sobre o processo e a organização do trabalho portuário e a maneira como os trabalhadores estão dando novos sentidos a este trabalho constituem um dos objetivos do projeto de pesquisa Processo de modernização portuária em Santos: implicações na saúde e adoecimento dos trabalhadores, com financiamento do CNPq, desenvolvida entre 2008 e 2011 (Queiróz et al., 2011). A análise apresentada neste artigo advém de estudo posterior de parte dos dados dessa pesquisa e direciona o olhar para a produção de subjetividade no contexto do trabalho portuário da cidade de Santos-SP, uma vez que as transformações ocorridas com a modernização dos portos estão marcadas na vivência de cada trabalhador e na vida de todo o coletivo de trabalhadores indiscriminadamente.

\section{Subjetividade como categoria de análise em saúde e trabalho}

Com a incorporação das ciências sociais ao estudo dos fenômenos saúde/doença, houve uma "mudança qualitativa", na medida em que transferiu a ênfase dada aos corpos biológicos para os corpos sociais - grupos, classes e relações sociais - implicados no processo saúde/doença (Minayo, 2008). Esta incorporação abriu novos olhares na área de saúde do trabalhador e possibilitou a inclusão da subjetividade como uma das dimensões a serem analisadas, ainda que no primeiro momento esta fosse tomada apenas como oposição à objetividade.

Essa abordagem trouxe reconhecimento e validação das dimensões psicológicas e simbólicas no contexto do trabalho. No final dos anos 1980, as análises provenientes da psicodinâmica do trabalho (Dejours, 1987; Dejours, Abdouchelli \& Jayet, 1994) privilegiavam a organização do trabalho como uma categoria fundamental para compreender o sofrimento proveniente do trabalho. Essas análises ressaltavam as relações cotidianas de trabalho, as relações entre os sujeitos, as questões de poder e os coletivos estabelecidos. No entanto, a referência à noção de subjetividade nas pesquisas desta abordagem frequentemente considera a subjetividade como uma dimensão centrada no sujeito, passível de sofrer influência ou dano por algum fator que lhe é externo. A subjetividade a que se referem remete à ideia de estrutura psíquica própria dos sujeitos e a inserção e vivência no trabalho.

Neste artigo, o que define a subjetividade é justamente a síntese do particular imbricada com o universo do trabalho. Esta perspectiva considera que o sujeito se constitui em suas relações com o mundo circundante e com os demais sujeitos envolvidos em seu cotidiano. O que aqui se denomina subjetividade é o campo de mediação que surge por meio das relações travadas com grupos a que o indivíduo pertence ao longo de sua vida. Por isso, parte-se da indissociabilidade entre indivíduo e sociedade como condição necessária para compreender os processos constantes de produção de subjetividade (Furtado, 2001).

Assim, a noção de subjetividade em destaque não é algo constituído internamente, tal como um mundo particular de emoções internas ao indivíduo. Sugere que ela se constitui ao longo da vida, nos encontros que o sujeito estabelece em seu cotidiano. Considerar a subjetividade como dimensão humana produzida incessantemente em cada encontro entre trabalhadores, máquinas e cargas significa privilegiar a compreensão das diferentes maneiras como homens e mulheres que vivem do trabalho produzem bens, serviços e a própria vida em cada momento histórico (Dalbello-Araujo, 2001). 
Na medida em que consideramos que a produção de subjetividade é constituída nas relações, em um universo histórico e social demarcado, a atual forma de organização do contexto do trabalhador portuário contém e está contida nas relações deste sujeito-trabalhador com o mundo que o cerca. Essa configuração gera modos de pensar, agir e viver que não pertencem aos trabalhadores em si, não estão contidos na peculiaridade do indivíduo per se, pois são construídos em um processo de constante transformação de si e do mundo que ocorre dentro de um espaço-tempo: o mundo do trabalho.

Desse modo, a subjetividade caracteriza-se pela expressão humana de um universo concreto em constante transformação que vai se definindo em um imbricado arranjo com o meio que o cerca, constituindo-se diariamente. Assim, este artigo pretende colaborar com a compreensão da subjetividade no sentido de uma produção contínua de modos de ser e viver, forjados no cotidiano dos trabalhadores portuários.

\section{Método}

Os aspectos elucidados neste artigo foram tratados de maneira qualitativa a partir de análise das entrevistas concedidas por ocasião da pesquisa ampliada Processo de modernização portuária em Santos: implicações na saúde e adoecimento dos trabalhadores, com financiamento do CNPq, desenvolvida entre 2008 e 2011.

Para sua elaboração, buscou-se valorizar o universo de significados, crenças e valores presentes nas falas dos trabalhadores portuários. A fim de compreender a dinâmica das relações sociais que constituem o sujeito, almejou-se a compreensão na sua forma mais profunda e abrangente, revelando uma apreensão necessária e possível para o complexo fenômeno analisado (Minayo, 2008). Em outras palavras, objetivou-se analisar a produção de subjetividade de trabalhadores portuários a partir do processo de modernização do Porto de Santos.

A seleção dos 30 trabalhadores entrevistados se deu de forma aleatória, por sorteio do banco de participantes da pesquisa maior, com 453 trabalhadores portuários avulsos, o que representa $11 \%$ dos 4.390 portuários na ativa. Deste total de participantes, procedeu-se a seleção por sorteio a fim de permitir a participação de qualquer categoria de trabalhadores. $\mathrm{O}$ sorteio tinha como meta abranger 30 trabalhadores, e aos sorteados foi feito o convite para participar da entrevista. Na recusa deste, passava-se para o próximo sorteado.

Os trabalhadores participantes estavam familiarizados com os pesquisadores, uma vez que já haviam respondido a um questionário anterior de abordagem quantitativa, o que facilitou o entendimento pelos trabalhadores do processo de pesquisa a que se submetiam. $\mathrm{O}$ contato com os trabalhadores ocorreu por via telefônica. O grupo de participantes foi, então, constituído por 30 trabalhadores, todos do sexo masculino, com idade média de 49 anos, residentes na cidade de Santos (20 trabalhadores), Guarujá (7), São Vicente (2) e Mongaguá (1). Vale lembrar que o trabalho portuário é eminentemente masculino; existem apenas duas mulheres entre os portuários avulsos, e as mesmas realizam atividades de conferência de carga.

Existem duas faixas de tempo de trabalho: uma com 16 trabalhadores com 13 a 24 anos de tempo de serviço e outra com 14 trabalhadores com 25 a 41 anos de trabalho. As categorias foram representadas por 11 estivadores, 6 vigias portuários, 5 trabalhadores de capatazia, 3 conferentes de carga, 2 operadores de guindastes, 1 feitor, 1 consertador de carga e 1 trabalhador de bloco. Dos trabalhadores entrevistados, 28 eram sindicalizados e 2 não sindicalizados.

\section{8}


Para coleta dos dados, utilizou-se um roteiro semiestruturado constituído de duas perguntas desencadeadoras que definiram os demais temas a serem explorados. Com este procedimento, tornou-se possível e indicado que o sujeito discorresse e verbalizasse seus pensamentos e reflexões sobre os temas apresentados: "seu trabalho em processo de modernização", "seus sentimentos para com este trabalho e com o processo de modernização" e o "significado das transformações do trabalho". O desenho inicial do roteiro foi gerado com participação dos próprios respondentes desde o início da pesquisa, quando se reuniu trabalhadores para a montagem do questionário da etapa quantitativa, precedente a esta etapa qualitativa da pesquisa. Assim, os termos e a linguagem estavam completamente adequados à linguagem do trabalhador portuário.

O roteiro da entrevista teve formulação flexível e versou sobre o cotidiano do trabalho no porto, a dinâmica deste espaço, as relações estabelecidas entre os trabalhadores e as transformações no processo de trabalho, entre outros elementos, pois sua sequência ficou por conta da própria formulação do entrevistado, permitindo assim um questionamento mais profundo e afetivo sobre cada assunto. Com essa forma de entrevistar, buscou-se garantir a riqueza de manifestações durante a entrevista, visto que, uma vez estabelecido o contato, foi possível construir um diálogo que permitiu também captar as expressões não verbais emitidas pelo sujeito no momento da entrevista.

As entrevistas foram realizadas nas dependências da Universidade Federal de São Paulo - Campus Baixada Santista ou no entorno do Porto de Santos, locais escolhidos pelos entrevistados de acordo com suas disponibilidades. Cada entrevista teve média de uma hora de duração. Elas foram registradas em gravador digital e, posteriormente, transcritas de maneira fidedigna. Após a transcrição, as entrevistas foram submetidas a análise de conteúdo (Bardin, 1995) com o intuito de construir as categorias, a posteriori, de modo a compreender o sentido e as significações, bem como aspectos implícitos e explícitos.

Em todos os passos, foram preservados a privacidade e o anonimato, garantidos pela assinatura do Termo de Consentimento Livre e Esclarecido e por cuidados éticos, conforme Resolução no 196/1996, do Conselho Nacional de Saúde. ${ }^{4}$

\section{Discussão dos resultados}

Os dados encontrados confirmam a importância de se revelar o cotidiano desses trabalhadores portuários e a produção de subjetividade neste contexto. Para a organização das informações de modo a facilitar a análise, os elementos em destaque nas falas dos trabalhadores foram inicialmente agrupados em quatro categorias consideradas mais relevantes para a investigação e condizentes com os objetivos propostos neste artigo. As categorias são: as transformações no trabalho, as atuais condições do trabalho, o papel do sindicato e do órgão de gestão da mão de obra (OGMO) e, por último, a saúde do trabalhador.

Para cada uma dessas categorias, foram criados núcleos de sentidos e significados. Assim, os relatos de situações que impactaram a vida do trabalhador portuário a partir da modernização, a entrada da tecnologia e a redução do número de trabalhadores em contraposição ao necessário trabalho braçal foram agrupados na primeira categoria, definida como transformações no trabalho. Seguindo a mesma linha analítica, os relatos sobre a construção e a desconstrução de coletivos e de importantes parcerias para a garantia da manutenção da empregabilidade foram agrupados na categoria atuais condições de trabalho, em que o cotidiano também revela situações de incertezas quanto a se ter trabalho. Já o papel do

4 A pesquisa foi analisada e aprovada pelo Comitê de Ética da Unifesp (CEP), processo no 0769/09. 
sindicato e do OGMO trouxe a cena relatos de individualização das lutas trabalhistas e a atual fragilização da organização sindical.

Após esse primeiro arranjo, seguiram-se nova leitura dos relatos e a condensação das falas para melhor compreensão dos conteúdos. Buscou-se, nas falas analisadas, compreender a produção de subjetividade em um contexto complexo que é o trabalho portuário. Para compreender se tal categoria permitia análise dessa construção subjetiva, procedeu-se a uma valorização dos conteúdos e de seus diversos sentidos, sem estabelecer hierarquização ou quantificação das categorias encontradas. Em seguida, decidiu-se apresentar uma única construção textual contemplando todas as categorias anteriormente definidas por se acreditar que, assim, revela-se a articulação de todas as categorias tal como encontradas nos relatos dos entrevistados.

\section{As transformações no trabalho e no cotidiano do trabalhador portuário}

Os trabalhadores portuários relatam as transformações do trabalho tendo em vista as situações que impactaram suas vidas a partir da modernização, assim como a entrada da mecanização e da tecnologia e a redução do número de trabalhadores em contraposição ao necessário trabalho braçal. Para Dalbello-Araujo (2001), o advento da globalização trouxe importantes modificações na estrutura portuária, com a imposição da competitividade, e por isso os portos nacionais tiveram de se enquadrar às normas mundiais para manter valores operacionais condizentes com os de outros portos mundiais.

Os participantes desta pesquisa indicam que o convívio de novas tecnologias com o trabalho braçal é necessário e que ainda há supremacia da força e da coragem como característica comum no cenário. Em diversas falas, o trabalhador indica a necessidade de força humana para o manejo das novas ferramentas e tecnologias do trabalho portuário:

Cortou homens no terno por causa de castanhas automáticas; a castanha é um equipamento que serve para acertar o contêiner, para fixar um contêiner no outro... Com aquela castanha, coloca um contêiner em cima do outro e encaixa um contêiner no outro, e a peação vem finalizando para poder segurar o contêiner no convés; então, essas castanhas servem para fixar um contêiner ao outro (P6).

No relato, o entrevistado destaca a redução do número de trabalhadores nos ternos. Como denominado por eles, um terno é o grupo de trabalhadores necessários para realizar o trabalho de carga e descarga em um navio específico. É uma equipe composta por diversas categorias de portuários, de acordo com a demanda e o tipo de carga a embarcar.

A fala acima também exemplifica o uso de castanhas automáticas como instrumental fundamental para o trânsito dos contêineres no porto. As castanhas são braçadeiras com fechos rotativos que fixam os contêineres ao convés ou ao porão dos navios. Para a sustentação de um contêiner, são utilizadas oito castanhas que unem os contêineres em seus quatro cantos, tanto em sua parte superior quanto na inferior. Sua função é mantê-lo fixado desde sua localização provisória até a localização destino. As castanhas possuem cabos que devem ser acionados para travar e destravar, fixando o contêiner suspenso até sua liberação no navio. As castanhas semiautomáticas requerem que o trabalhador as manuseie e puxe o cabo para a função de travar-destravar. Já as castanhas automáticas são utilizadas no convés dos navios e não possuem cabos, pois travam automaticamente, eliminando a necessidade de um trabalhador para esta tarefa específica. A atividade de "peação", tal como relatada, é o trabalho, subsequente, em que o portuário realiza, nos navios, a arrumação das cargas, que seguem até seu destino final. 
O relato seguinte descreve essas tarefas realizadas no porto. $\mathrm{O}$ trabalhador, ao se referir à redução do número de colegas em seu turno de trabalho, confirma o convívio das novas tecnologias com a necessária manutenção da mão de obra do portuário em situação de contínuo risco, tal como destacado em fala sobre a altura em que o trabalhador deve desenvolver suas atividades:

O trabalho de contêiner hoje é automatizado, mas, em si, não é 100\% automatizado... porque o trabalhador tem de destravar a castanha, tem de subir a uma altura de 6, 7 de alto. Um contêiner [tem] um metro e oitenta cada um, então imagina 6, 7 contêineres, um em cima do outro, mais a altura do navio, então vai lá no alto, para destravar (P27).

As falas dos trabalhadores apontam as mudanças que vieram com as exigências de novas tarefas com a introdução do contêiner. De um lado, a castanha automática dispensa a ação do ser humano, e, de outro, as semiautomáticas, que também são equipamentos modernos, exigem do trabalhador subir "lá no alto".

Em entrevista, os trabalhadores afirmam que a maioria dos navios que atracam no porto de Santos não possui castanhas automáticas, fato que, para eles, não justificaria a redução de trabalhadores no terno. Tem-se a mesma exigência de trabalho com um contingente menor de trabalhadores portuários. Entende-se, portanto, que a finalização do trabalho semiautomatizado depende de o trabalhador fechar a peação (arrumação) da carga e exercer com seu corpo e sua força a parte final de um trabalho tecnológico moderno.

De acordo com Santos (2001), um aspecto que tem apresentado grandes dificuldades é ajustar a quantidade de trabalhadores registrados e a quantidade de trabalhadores necessários para a execução da tarefa de carga e descarga de um navio em função do tipo de embarcação, da carga a ser processada, do tipo de embalagem utilizada e do equipamento a ser utilizado na operação. Assim, os relatos se referem às mudanças na forma de embalagem:

[Antes]... a gente carregava aquelas caixas. Depois, mudou para umas caixinhas de $20 \mathrm{~kg}$, de madeira, que arranhavam, machucavam o trabalhador. Depois, mudou para caixas de papelão, ficou mais suave o trabalho. Porque ele agredia menos o físico do trabalhador, era mais fácil a manipulação, tinha onde pôr a mão na caixinha para você arrumar, houve uma facilidade. Depois veio a "unitização" da carga, que é a paletização. A laranja basicamente, a gente não vê mais embarcar no porão (P10).

A paletização corresponde ao processo pelo qual vários volumes (sacos, caixas, tambores, rolos de arame etc.) são empilhados sobre um estrado, amarrados com fitas e limitados por cantoneiras laterais. A paletização mudou o patamar operacional das empresas, pois a unidade logística deixou de ser a caixa e passou a ser o palete, e estes ainda podem ser unitizados em contêiner, como já esclarecido anteriormente. Vários portuários indicam que é necessário adequar os contêineres ao novo cenário de modernização portuária, pois as novas tecnologias demandam que os mesmos "remem a favor da maré":

Você tem de remar a favor da maré. Então, quer dizer: aquelas cargas, que eram cargas gerais, eram cargas soltas que a gente ia estivando no porão do navio, hoje estão indo dentro dos contêineres... e tudo isso se otimizou dentro dos contêineres. Então, nós perdemos muito com o contêiner (P6).

Santos (2001) afirma ainda que, embora esse debate pareça, à primeira vista, eminentemente técnico, ele também é carregado de componentes políticos, uma vez que implica o ritmo de trabalho a ser desenvolvido nessas operações, além de se reduzir a remuneração dos trabalhadores, já que estes terão possibilidades menores de engajamento no trabalho. Isso leva a acreditar que, até aqui, a frágil base dessa justificativa é que os trabalhadores estão sendo beneficiados, pois ocorre a regularização dos ganhos destes por meio de uma garantia de remuneração, desde que haja redução nos registros e não exista mais a 
obrigatoriedade de se atuar com trabalhadores registrados nos termos da Lei de Modernização dos Portos.

Ainda que a Lei $\mathrm{n}^{\mathbf{0}}$ 8.630/93, por um lado, garanta a inserção do trabalhador avulso, por meio da tomada de trabalho, por outro, ela permite a contratação de trabalhadores em regime da CLT (Consolidação das Leis de Trabalho), denominado vinculado. A nova modalidade de trabalho, vinculado, é apresentada na Lei no 8.630/93 não como uma forma única e impositiva, mas com interpretações que favorecem as operadoras portuárias. O vínculo empregatício já era uma prática na área retroportuária, mas não para os trabalhadores do porto nas atividades no costado e no navio. Ao mesmo tempo em que a Lei $\mathrm{n}^{\mathrm{0}}$ 8.630/93 assegura o trabalho portuário avulso, ela favorece a vinculação. E este é um sentimento expresso pelo trabalhador em sua fala sobre ser avulso e a pressão para se tornar vinculado:

Mas é aquele negócio, né? Nosso tipo de trabalho, hoje, é aquele tipo... o operador portuário acha que não há necessidade de avulsos. Eles querem vínculo. Eles querem operador vinculado. Então, quer dizer, dá aquele desleixo, entendeu? Você chega no trabalho, vai perguntar pro funcionário lá de uma operadora como é que vai ser o trabalho. Eles não te passam o trabalho, fica aquele clima entre vinculado e avulso... acabarem com os avulsos, que é o que esses funcionários, esses patrões, estão querendo fazer, para que eles coloquem aí uma mão de obra escrava, entendeu? (P18).

Eles não querem passar o trabalho pra gente. "Oh... vai embarcar tantos contêineres, vai tantos contêineres, e depois vai ter de colocar tantas castanhas...”. Eles não falam... a gente fica naquela, né? A gente tem de ficar ali à disposição, até a hora que precisar, que vai acontecer alguma coisa e realmente precisar. Aí vem e fala: "Olha, tem de colocar a castanha ali no piso que vai pegar uns contêineres". Se a gente já sabe o que vai fazer, a gente já se organiza, né? "Olha, vai embarcar os contêineres na sela, no porão, né? E depois vai ser colocado o tampão, vai pegar contêiner de vinte.” Então a gente já pega tantas castanhas e já deixa na posição que, quando colocar o tampão, a gente vai colocar as castanhas pra pegar o contêiner de vinte. $O$ pessoal que trabalha no conexo, muitas vezes, o material não está à disposição para ser feita a peação. Às vezes, o navio vem de fora, ele vem vazio. Daí eles começam a agitar a gente. Daí não dá, né? Na correria, acaba acontecendo acidentes, entendeu? (P20).

Os trabalhadores destacam que a unitização da carga, por meio da arrumação desta em contêineres, demanda número menor de pessoas para o trabalho, acelera o ritmo e diminui as relações que construíram no trabalho nas décadas passadas, pois, além da própria característica organizativa do trabalho moderno, foi reduzido o tempo que as pessoas permanecem juntas trabalhando.

Hoje um navio chega aí no cais, ele atraca de manhã, à tarde ele está indo embora. Antigamente, quando não existia o contêiner, o navio ficava 15, 20 dias, pois a carga ia solta. Até a década de 1970, que eu me lembro, as cargas vinham tudo solta, daí era aquela descarga morosa, embarque também era moroso... Hoje, não: tem os equipamentos, para a agilidade que eles querem... (P1).

Podemos depreender disso que o trabalho anterior demandava número maior de trabalhadores, que permaneceriam mais tempo juntos em torno de uma mesma atividade e que isso favorecia a construção de laços de confiança e solidariedade no porto. Há também, nos relatos, constante preocupação quanto à redução do número de trabalhadores e ao impacto dessa redução na carga de trabalho realizado e no ganho salarial.

Antigamente, eram usados 8 homens em um terno, para embarcar uma carga. Hoje, se usam 3, porque hoje a carga vai dentro do contêiner... perdeu o campo de trabalho. Onde se tiravam 8 homens, hoje se tiram 3. Você perdeu 5 homens. Uma turma de 200... demorava 15 dias para os 200 trabalhar, e agora demora 35 para os 200 trabalhar, porque diminuiu o número de trabalhadores, pela modernização (P26). 
Quer dizer, eu tive duas reduções: eu tive redução de contingente e redução do ganho. Então, eu empobreci. (P6)

Por outro lado, eles também reconhecem que a tecnologia contribuiu para minimizar a exaustão do trabalho braçal anterior:

Então quer dizer, naquela época, era mais sofrido. Era tudo no braço. Hoje é tudo automatizado.

Hoje, pega uma máquina no granel, põe uma máquina para ir chegando, só desce para quebrar sarreta (P1).

Ao adotarem uma política de progresso tecnológico, os portos passaram a se relacionar com fornecedores estrangeiros de equipamentos portuários de última geração. Os relatos dos entrevistados sugerem que no porto prioriza-se a automatização dos embarques e desembarques e que, neste contexto, as atividades realizadas não devem desprezar o trabalho humano, uma vez que a intervenção humana será sempre fundamental para o trabalho portuário. É o que acontece no caso explicitado a seguir, em que o trabalhador se refere à atividade de limpeza do produto na área de sustentação dos porões no navio, a que chamam de sarreta.

Já na estiva, tem contramestre, tratorista, guincheiro, motorista de empilhadeira... sinaleiro... existe esse montão de função. Por isso que tem que ter ainda um toque manual do trabalhador. Porque a máquina não vai conseguir fazer isso tudo. Vai enriquecer de detalhes, vai dar pane no sistema e não vai dar certo... (P27).

O trabalhador tem que descer para acompanhar a limpeza das sarretas, que vêm nas laterais do navio. A sarreta, que é uma sustentação dos porões do navio, e o produto fica preso ali, e o trabalhador tem de descer com a picareta, com pá, com varão, para o produto descer (P9).

O relato a seguir revela com humor uma situação comum em que o saber do trabalhador é fundamental para a finalização do trabalho executado.

Além disso, existe a tal da castanha inteligente, que deu um golpe no trabalhador, que de inteligente ela não tem nada. Precisa do trabalhador para colocar ela e para retirar. Outro dia aconteceu um fato curioso. O cara falou para mim: "O senhor tem que descer para botar uma castanha". E eu falei: "Eu, não. O teu patrão falou que é inteligente: você assobia que ela vai para o lugar, ela é inteligente, ela entende". Aí o cara ficou bravo comigo (P10).

Ao considerarmos tais argumentos, parece que, aos olhos do trabalhador, ainda não se atingiu um equilíbrio entre o elemento humano e os processos automatizados. Para Santos (2001), é necessário que se realizem programas contínuos de formação avançada, a fim de se conseguir uma mão de obra tecnologicamente competente e integrada: operadores, pessoal de segurança e manutenção adequadamente qualificados, com atitudes e organizações, tanto de supervisão quanto de relações humanas, mais solidamente fundamentadas para este setor de trabalho.

As entrevistas desenvolvidas com os trabalhadores portuários também revelam que existe um passado de relações solidamente sustentadas neste contexto que permitiu construir um coletivo de trabalho. Entendemos que esse coletivo deve ser considerado pelas operadoras portuárias, já que, para os entrevistados, estas investem muito mais na formação e no treinamento de seus próprios quadros de funcionários do que no treinamento dos trabalhadores avulsos, os quais, muitas vezes, sentem-se desqualificados.

Segundo os entrevistados, para que o trabalho possa se desenvolver, é fundamental haver sinalização e diálogo corporal entre os membros do terno ou do coletivo, o que faz com que o trabalhador se sinta ator importante no processo e, certamente, contribui para a manutenção de sua saúde em plena movimentação intensa de cargas em um porto em contínua função. As relações de solidariedade e de cuidado pessoal, em nome da segurança no trabalho, também transparecem nas falas. Assim, para os participantes, a redução do número de 
trabalhadores também diminuiu o cuidado de um trabalhador para com a segurança de seus parceiros de atividade, aumentando o risco de acidentes:

Tirou mais homens, eu acredito que até aumente o risco, porque antes um cuidava do outro... Agora, com 3 homens, já é mais difícil um cuidar do outro. Um tem que ficar lá, o outro aqui, às vezes um não enxerga o outro (P26).

Segundo Sato (2002), o replanejamento do trabalho provoca preocupações quanto à saúde do trabalhador e aos acidentes de trabalho. A autora evidencia que os trabalhadores criam formas para resistir à racionalidade da organização do trabalho, o que pode denunciar que buscam melhorar a sintonia entre eles e os contextos de trabalho, de modo individual e coletivo.

Os fortes laços construídos no trabalho do porto sustentam uma cultura muito peculiar. Assim, tanto a linguagem corporal como a oral são importantes componentes da manutenção da saúde e da segurança no trabalho. Em várias situações, os trabalhadores sinalizam a importância da comunicação para a garantia da segurança no trabalho, que passa a ficar em suas próprias mãos, sustentada por laços afetivos. Há relatos de construção de coletivos e de importantes parcerias para execução de atividades, e insinuam-se diversos indicativos da necessária familiaridade com o universo do porto para a efetivação das várias atividades do setor:

Agora, com menos homens, se eu tirar um homem aqui, quem vai me avisar? Se eu não me cuidar, se eu não tomar cuidado? Agora, se eu deixar de olhar para cá, eu vou deixar a carga derramar ali... E se eu cuidar daqui, eu posso tomar uma porrada daqui, entendeu? Essa modernização, baixa de homens, fica mais complicada, gera mais incidente, é mais fácil de acontecerem acidentes. Principalmente à noite, que não é a mesma iluminação, a visão já não funciona igual, tem o cansaço físico, de sono mesmo, que é natural do ser humano. Aqui, tem de fazer alguma coisa para que todo mundo se sinta bem, ninguém se machuque. A gente tem de preservar o coletivo. Não adianta pensar na gente, sempre tem de pensar no coletivo (P26).

Antes do advento das mudanças implementadas pela citada lei, o trabalho se configurava por laços sustentados por uma coletividade, que se tornou um importante componente do trabalho e da segurança. Após o início da modernização, os laços já não são suportes para a realização do trabalho, ora administrado pelos detentores do capital. $\mathrm{O}$ sentimento de segurança, atualmente, além de ser percebido como frágil, é inconsistente e descontínuo, pois não oferece a efetiva segurança no trabalho. E os trabalhadores, por seu lado, não percebem que sua segurança é uma ação obrigatória por parte dos órgãos responsáveis pela requisição/contratação da mão de obra.

Dalbello-Araujo (2001) afirma que os trabalhadores portuários encontram várias formas de atenuar os riscos de acidente e de doenças relacionadas ao trabalho realizado. Em pesquisa realizada entre os trabalhadores de sete portos do estado do Espírito Santo, verificou as sutis relações entre a organização do trabalho e a saúde e a segurança engendradas pelo cotidiano de trabalho e percebeu que, naquele contexto, as formas de comunicação gestual e ajuda mútua eram fundamentais para evitar que muitos acidentes ocorressem durante a realização do trabalho.

Com a diminuição do número de trabalhadores por equipe (ternos), a intensificação da produtividade e o aumento do volume de trabalho, a organização anterior sofreu fortes transformações. Este cotidiano também revela situações de incertezas quanto a se ter trabalho, advindo das mudanças na seleção dos trabalhadores para os ternos.

Vive-se essa pressão, hoje em dia mesmo... pode perguntar para qualquer trabalhador, nenhum trabalhador está se sentindo que nem antigamente, que era garantido, que não vai ser mandado embora, que vai ter emprego para sempre. Hoje o estivador, ele já sai de casa com medo: "O que será que vai acontecer hoje?" (P27). 
Os entrevistados deixam transparecer que as adequações a esta norma foram implantadas sob certa resistência por parte dos trabalhadores, visto que implica um novo ambiente de trabalho e provoca novos arranjos e mudanças significativas no cotidiano de trabalho, principalmente sobre o novo sistema de remuneração, baseado na produção. Este ambiente de conflito e carregado de tensão gera certa instabilidade, e os trabalhadores trazem, em fala, um saudosismo em relação ao tempo anterior à modernização.

Em vários momentos das entrevistas, os trabalhadores referem a sensação de lesão a seus direitos. Trazem sentimentos de medo, receio e pressão, gerados pela indefinição e pela falta de garantias quanto a ter ou não um trabalho no dia seguinte. Há um contínuo "medo do amanhã", frequente nas entrevistas. Além disso, há também uma tentativa de "ressignificação do amanhã": "Se chegar e não tiver trabalho, volta para casa e não ganha nada. Se tiver trabalho, trabalha. Se não tiver, não trabalha" (P9).

A gente está vivendo com medo hoje em dia. O nosso trabalho ali é seis meses de alegria e seis meses de tristeza. Seis meses, tu ganha legal, e seis meses, tu ganha mal. Aí, o que acontece? Acumula contas nesses seis meses que são ruins para pagar nesses seis meses que são bons (P4).

Só tem o problema desse medo do amanhã, que a gente não sabe como vai ser. Porque sempre eles estão tentando alguma coisa contra a gente. A toda hora, é uma pressãozinha daqui, uma pressãozinha dali. E a gente fica no meio, pelo menos eu que tenho mais de 20 anos para ficar ali, eu fico meio receoso (P27).

Ainda assim, neste cenário de modernização portuária que busca a automatização do trabalho, existe, paralelamente às transformações tecnológicas, certa autonomia do trabalhador, que sugere a existência de uma estratégia, realizada por meio de negociações implícitas e exclusivas de seu universo, para a superação das condições de produção de sofrimento na execução de seu trabalho:

Essa profissão aqui foi a que eu mais me identifiquei... por quê? Liberdade, liberdade. Você tem liberdade, mas tem de saber usar ela também, tem gente que abusa (P29).

Há forte referência saudosista ao período em que o trabalho avulso era demandado diretamente do porto, mediado pelos sindicatos representantes das categorias, em que o portuário sentia mais autonomia em seu trabalho e decidia onde, quando e com que equipe preferia trabalhar.

Aquilo não é uma escala eletrônica... é um jogo de azar... aquilo simplesmente é um jogo de roleta. Por quê? Você não sabe exatamente qual é o navio, qual é a carga, qual é o porão, quem trabalha, com o que tu trabalhas... Antes, quando o sindicato fazia a tiragem, ia lá, "porão 1, tantas toneladas de carga tal", ou então "tem carga isso, carga aquilo, carga aquilo outro, trabalha com guincho de bordo...", sabe? Te dava as coordenadas porão por porão (P11).

Quando o controlista pedia, ele já pedia direito, porque o trabalho ia para o sindicato dele, os amigos dele iam escolher. E os estivadores iam escolher, os consertadores, e assim por diante. Todo mundo escolhia o trabalho porque era interesse dos trabalhadores. Hoje, não... não há um controlista que faz isso. Hoje, a empresa que chega lá, "ah, vou tirar, não vou tirar...", muitas vezes não tira consertador e precisa de consertador... (P11).

O que eu gosto mesmo é que é um lugar que você trabalhou e já vem o dinheiro. Você trabalhou, você sabe quanto é que você vai ganhar, e é isso que é legal de trabalhar no porto. Tem a tua liberdade, não está a fim de trabalhar hoje, quer sair, não é o trabalho que vai te segurar. Tu vai embora, isso que é o legal desse trabalho (P27).

Segundo Santos (2001), estes trabalhadores estão em um ambiente de conflito, pois tiveram de adequar suas estratégias de luta, passando a discutir temas antes relegados a segundo plano, tais como as políticas ambientais para o porto e suas consequências para a saúde do trabalhador. E destacam a transformação em norma regulamentadora da Convenção 
no 152 da Organização Internacional do Trabalho (OIT) sobre saúde e segurança nos trabalhos portuários.

Por outro lado, deve-se dar o devido destaque às diversas falas que trazem argumentos afetivos sobre o trabalho do porto. Há um saudosismo sobre o modo como se constituiu historicamente esta categoria de trabalhadores.

Trabalhar no porto é uma coisa que poucas pessoas entendem, porque trabalhar no porto não é só... um local de trabalho, trabalhar no porto, pra gente, que já vem de avós, de pai... tem irmão, temos a família trabalhando no porto, o porto para Santos é uma importância que tem pra cidade, porque tanto é... a nossa renda é o que segura a cidade, a Baixada Santista depende do trabalho do trabalhador portuário avulso... e além, também, de você pertencer a uma família, no caso a família portuária, a família estivadora, isso faz você trabalhar tanto, você trabalhar com mais vontade, faz te dar prazer em trabalhar, você pertencer a uma família que já vem do porto e você pertencer a isso e saber que você é... muito importante pra Baixada Santista, que você faz movimentar o capital na Baixada... depois da modernização, é... o capital, ele ficou escasso, porque, antes da modernização, é igual te falavam antigamente, as pessoas mais antigas que trabalham no porto... o capital girava com mais facilidade (P6).

Os entrevistados assinalam um ambiente de trabalho marcado por fortes relações de afetividade e parentesco entre as diversas categorias portuárias. Acentuam-se ainda a necessidade e a dependência da atividade física, sendo imperativo um corpo forte e saudável para a manutenção do trabalho. Por isso, parece de fundamental importância que se analise a condição de trabalho e de saúde partindo da subjetividade e do conhecimento advindo do próprio universo do trabalhador (Sato, Lacaz \& Bernardo, 2006).

A internacionalização do Porto de Santos, como um dos aspectos da globalização da economia, e a implementação de tecnologia no embarque e desembarque de cargas são objetivos visíveis nas ações governamentais e afetam o cotidiano dos trabalhadores portuários. Antes do processo de modernização do setor portuário, havia uma modalidade de trabalho que favorecia a iniciativa do trabalhador e a construção de certa autonomia e liberdade nas ações destes, assim como a organização do trabalho. Configurava-se um trabalho estruturado e organizado pelos próprios trabalhadores, tendo como pilares suas organizações sindicais de categorias. Havia forte construção de coletivo, de característica familiar, na constituição do trabalho, com relações de parceria e confiança que sustentavam cada trabalhador em sua função e garantiam sua permanência no trabalho.

Esse forte vínculo levava o portuário a sentir-se "dono" de seu trabalho, com o controle do tempo e de sua atividade. Atualmente, há uma peculiaridade neste campo de trabalho que esmaece a figura da empresa, pois em seu lugar aparece sempre o porto, numa rede complexa de relações hierárquicas, de cooperação e de dependência coexistentes e inter-relacionadas. No caso santista, a figura da empresa é diluída também nos diversos sindicatos que, antes de fortalecer uma ou outra categoria, se confundem com a perspectiva institucional.

A especificidade dessa modalidade de trabalho ainda requer grande esforço muscular, com exigência de posturas antinaturais, que incidem em perigos contra a vida (DalbelloAraujo, 2001). A postura é uma atitude adotada pelo corpo, uma disposição do corpo no espaço. A postura natural deve ser aquela em que, segundo os princípios da biomecânica, as articulações ocupem posição neutra, ou seja, sem movimentos como, por exemplo, de extensão, flexão ou inclinação. Deve ser uma postura que não requeira grande esforço para mantê-la e, assim, não prejudique o organismo, não crie sobrecargas funcionais ou condições que, a longo ou curto prazo, possam originar processos patológicos (Queiróz, 1998). Posturas exigidas para a realização do trabalho que não permitam ao trabalhador se acomodar em uma postura natural são, portanto, consideradas antinaturais.

Esta análise afasta-se cada vez mais de concepções e práticas patologizantes, que compreendem a subjetividade como se fosse uma questão individual, pois toda transformação 
no mundo do trabalho gera transformações no homem que trabalha e que também se modela no trabalho enquanto produz bens e serviços, eterno ciclo de produção de novas subjetividades.

\section{Considerações finais}

Ao objetivar a análise da produção de subjetividade no contexto do trabalho portuário em Santos, este artigo defende que as transformações ocorridas com a modernização dos portos estão marcadas na vivência de cada trabalhador ao mesmo tempo que influenciam a vida de todo o coletivo de trabalhadores.

A modernização altera as relações de trabalho e, por sua importância, gera novas subjetividades. A base do trabalho portuário até o advento do contêiner, por volta de 1960, caracterizava-se pela força física do trabalhador, um mundo masculino, aparentemente estável e seguro. Daí a imagem viril deste tipo de trabalho, em que o corpo revela uma modelação da própria atividade cotidiana. Por outro lado, acentuou a necessidade e a dependência de atividade física, marcando a necessidade de um corpo forte e saudável para a manutenção do trabalho. Havia um corpo esculpido no dia a dia do ofício portuário que facilitava a afirmação da saúde e da juventude dessa profissão.

Além disso, até a chegada da modernização ao setor, havia uma modalidade de trabalho que também favorecia a iniciativa do trabalhador e a construção de certa autonomia e liberdade nas ações dos trabalhadores, assim como a organização do trabalho. Destaca-se também a forte construção de um coletivo na constituição do trabalho, com relações de parceria e confiança que sustentavam cada trabalhador em sua função e garantiam sua permanência no trabalho, e hoje esmaece no cenário inaugurado por diversas empresas participantes da atividade portuária.

O processo de modernização e a nova gestão do trabalho portuário abalaram profundamente essa cultura de trabalho sustentada em relações de confiança e parceria. Neste cenário, o trabalho pode ser compreendido como fonte permanente de recriação de formas de viver e de produção de sujeitos capazes de produzir maneiras de enfrentar novas e velhas situações, confrontando-se com sua própria experiência, bem como com a de outros trabalhadores.

Partindo da verificação de que o processo de modernização modifica as relações de trabalho, entende-se que essa nova realidade convoca vários olhares para a situação do trabalhador e suas condições de trabalho, o que demanda também maior investimento para analisar os processos subjetivos engendrados neste universo, já que por meio do trabalho se produzem bens e serviços ao mesmo tempo em que está sendo gerado um novo homem. Depreende-se deste estudo a necessidade de ampliar pesquisas em que haja a participação dos trabalhadores para avaliar aquilo que está sendo produzido no trabalho como modos de existir e sofrimentos psíquicos advindos deste. Para isso, são precisos uma análise que parta da dimensão do trabalhador e, necessariamente, a participação do saber que advém da experiência daquele que vivencia todo o processo.

\section{Referências}

Aguiar, M. A. F., Junqueira, L. A. P. \& Freddo, A. C. M. (2006). O Sindicato dos Estivadores do Porto de Santos e o processo de modernização portuária. Revista de Administração Pública, 40 (6), 997-1017. 
André, M. M. (1998). A organização do trabalho portuário: o cotidiano de vida e o trabalho dos portuários avulsos. Vitória: Edufes.

Araújo, H. P. P \& Pereira, J. A. (2007). Santos: uma história de pioneiros, piratas, revoltas, epidemias, carnaval e futebol. Santos: Realejo Edições.

Bardin, L. (1995). Análise de conteúdo. Lisboa: Edições 70.

Companhia das Docas do Estado de São Paulo (s. d.). Resumo completo da história do Porto de Santos. Recuperado em 6 de fevereiro de 2011, de http//www.portodesantos.com.br/historia.php.

Dalbello-Araujo, M. (2001). Psicologia social, trabalho e contemporaneidade: o trabalho portuário e suas vicissitudes. In H. Novo, L. Souza. \& A. Andrade (Orgs.), Ética, cidadania e participação: debates no campo da Psicologia. Vitória: Edufes.

Dejours, C. (1987). A loucura do trabalho: estudo de psicopatologia do trabalho. São Paulo: Cortez/Oboré.

Dejours, C., Abdoucheli, E. \& Jayet, C. (1994). Psicodinâmica do trabalho: contribuição da escola dejouriana à análise da relação prazer, sofrimento e trabalho. São Paulo: Atlas.

Freddo, A. C. (2002). Modernização portuária, poder e violência. In L. A. P. Junqueira (Org.), Desafios da modernização portuária. São Paulo: Aduaneiras.

Furtado, O. (2001). O psiquismo e a subjetividade social. In A. M. M. Bock, M. G. M. Gonçalves \& O. Furtado (Orgs.), Psicologia sócio-histórica: uma perspectiva crítica em psicologia. São Paulo: Cortez.

Gitahy, M. G. (1992). Ventos do mar: trabalhadores do porto, movimento operário e cultura urbana em Santos, 1889. 1914. São Paulo: Editora da Unesp.

Gonçalves, A. \& Nunes, L. A. P. (2008). O Grande Porto: a modernização no porto de Santos. Santos: Realejo Edições.

Junqueira, L. (2002). Desafios da modernização portuária. São Paulo: Aduaneiras.

Lei no 8.630, de 25 de fevereiro de 1993 (1993). Dispõe sobre o regime jurídico da exploração dos portos organizados e das instalações portuárias e dá outras providências (Lei dos Portos). Diário Oficial da União, Seção 1, p. 2351-2356. Brasília.

Merhy, E. E. (1985). O capitalismo e a saúde pública. São Paulo: Papirus.

Minayo, M. C. (2008). O desafio do conhecimento: pesquisa qualitativa em saúde (11ํㅡ ed.). São Paulo: Hucitec/Abrasco.

Queiróz, M. F. F., Machin, R., Tucci, A., Nakamura, E., Couto, M. T., Medeiros, M. A. T. et al. (2011). Processo de modernização portuária em Santos: implicações na saúde e adoecimento dos trabalhadores. Santos (Relatório de Pesquisa-CNPq).

Queiróz, M. F. F. (1998). Estudo comparativo de dois postos de trabalho na indústria automática e manual de vidro. Dissertação de Mestrado, Universidade de São Paulo, São Paulo.

Santos, L. F. B. (2001). Resistir, a quem se destina? O caso do setor portuário. In L. H. Borges, M. G. B. Moulin \& M. D. Araújo (Orgs.), Organização do trabalho e saúde: múltiplas relações. Vitoria: Edufes.

Sato, L. (2002). Prevenção de agravos à saúde do trabalhador: replanejando o trabalho através das negociações cotidianas. Cadernos de Saúde Pública, 18 (5), 1147-1157.

Sato, L., Lacaz, F. A. C. \& Bernardo, M. H. (2006). Psicologia e saúde do trabalhador: práticas e investigações na Saúde Pública de São Paulo. Estudos de Psicologia, 11 (3), 281-288.

Silva, S. O. (2007). As ações de saúde do trabalhador como dispositivo de intervenção nas relações de trabalho. In E. M. Rosa, H. Novo, M. E. B. Barros \& M. I. B. Moreira (Orgs.), Psicologia e saúde: desafios às políticas públicas no Brasil. Vitória: Edufes.

\section{Endereço para correspondência}

fatima.queiroz@unifesp.br,mibadaro@gmail.com, dalbello@intervip.com.br

Recebido em: 21/09/2011

Revisado em: 29/06/2012

Aprovado em: 04/07/2012 